\title{
Agricultural Lifestyle, Perspectives and Conservational Issues in Protected Areas: A Study of Human-Elephant Conflict in Pidurangala in the Central Province of Sri Lanka
}

\author{
RANAWEERAGE Eranga \\ Department of Tourism Science, Graduate School of Urban Environmental Sciences, Tokyo Metropolitan University; \\ 1-1 Minami-Osawa, Hachioji-shi, Tokyo 192-0397, Japan. \\ E-mail: ranaweerage-eranga@ed.tmu.ac.jp
}

Received January 27, 2012; Accepted August 6, 2012

\begin{abstract}
People and wild animals constantly compete for limited resources of the planet, and mitigating these conflicts to allow co-existence is key to the well being of the world. This research revealed a conflict between an agricultural community and wild elephants in the Central Province of Sri Lanka, in a protected area where people and elephants exist within the same boundary sharing the natural resources directly. The conflict negatively impacted on the lives of people as well as elephants as there were both elephant-induced damage and human-induced damage. The change in attitudes and increased intolerance of farmers towards elephants as a consequence of the new conservation rules and regulations in the area added to the intensity of the conflict. Community support and involvement in the conservation process and the value of traditional livelihood are important factors in mitigating the issue.
\end{abstract}

Key words agricultural lifestyle, conservational rules, protected areas, human-induced damage, elephant-induced damage

\section{Introduction}

Today, people and wildlife increasingly come into conflict over living space and resources (Kiiru 1995; Barnes 1996; Sitati et al. 2003). Many of the people affected by such conflicts are some of the most impoverished on earth, and tend to suffer higher economic and social costs. On the other hand, these conflicts affect the population viability of some of the most endangered species, and have broader environmental impacts (Distefano 2005).

Human-Elephant Conflict (abbreviated HEC throughout this paper) is defined as "any human-elephant interaction which results in negative effects on human social, economic, or cultural life, on elephant conservation, or on the environment" (IUCN/SSC African Elephant Specialist Group). HEC is considered as one of the most serious human-wildlife conflicts as it involves the largest terrestrial animal in the world. Desai (1998) explains HEC as a consequence of the diversion of elephant habitat by people. The issue is particularly intense in agrarian societies (Ishwaran 2001), and the agricultural communities living in and around protected areas are mostly experiencing HEC (Parker and Osborn 2001). However, the spatial patterns of the conflict have been difficult to identify and have shown few universal trends, making it difficult to predict where the conflict will take place (Sitati et al. 2003). According to Perera (2009), there is an inadequate HEC database which hampers the efforts towards its mitigation.

In Sri Lanka, this conflict results in the death of 150 elephants and 50 to 70 people on average every year. Previous HEC research in Sri Lanka was mainly focused on Northwestern, Eastern and Southern regions. The three regions consist of large national parks and nature reserves with a large number of elephants and the areas around the parks are inhabited by over 1.5 million people. However, in these cases, there are no private lands or communities living within the parks. In other words, territories of people and elephants are separated by park boundaries which make the mitigation of HEC somewhat possible.

The regions like Central Province with small herds of elephants have received significantly less attention and HEC data or research is highly inadequate. However, the region consists of areas where people and elephants co-exist, sharing the natural resources directly, which is a different scenario from the previously explained parks and reserves. Therefore, this paper revealed a case of HEC 




Figure 1. Research site-Pidurangala.

in an area called "Pidurangala" in the Central Province (Figure 1) where there is direct co-existence of people and elephants.

Three methods were adopted for data collection. First, face to face interviews with the local administrative officers and the residents were conducted to learn about the occurrence of HEC, attitudes towards the issue and the current actions taken for mitigation. 41 local residents extended their participation in the interviews among which 22 were males and 19 were females. Second, an enumerator reporting system was used along with a specific damage report form to record and report HEC incidents for a period of one year from May 2009 to April 2010. This damage report form was adapted from the HEC data collecting protocol developed by Hoare (1999), and targeted data such as type of damage incident (crop damage, property damage, human or elephant death/injury), date, time and the location of the incident and the level of damage. Third, a GPS survey was carried out to find out the spatial distribution of damage incidents in the area.

\section{Protected Area Category, Demography and Land Use of the Study Site}

Pidurangala is located in Matale District in the Central province of Sri Lanka. It belongs to a protected area category called "Sanctuary". The area became a sanctuary in 1990. Sanctuaries are created to ensure the protection of wildlife. The difference between a sanctuary and other protected areas in Sri Lanka is that sanctuaries may include private lands with people living within them. It is not necessary to obtain a permit to enter into a sanctuary. However, human activities are regulated by a legal act called "Fauna and Flora Protection Ordinance (FFPO)". For example, hunting, poaching, or killing of wildlife, clearing forest or cutting trees and any form of construction are prohibited not only in the state lands, but also it is required to obtain a special permit for such activities within private lands of a sanctuary. The exact number of elephants in the area is uncertain, however is expected to be around 30 to 40 elephants ${ }^{1}$. The dominant vegetation is shrubs, dry evergreen forests and moist deciduous forests which provide habitat for wild elephants in the area.

The total human population of Piduranga was 565 including 281 males and 284 females in 176 families (2009 population data, Pidurangala Public Administration Authority). The majority of the families were originally from Pidurangala as there were only five families new to the area. Over 99\% of the population (561 people) was Buddhist and only less than 1\% (4 people) was catholic. The main economic activity of the area was agriculture and about $90 \%$ of the population was farmers. The average 


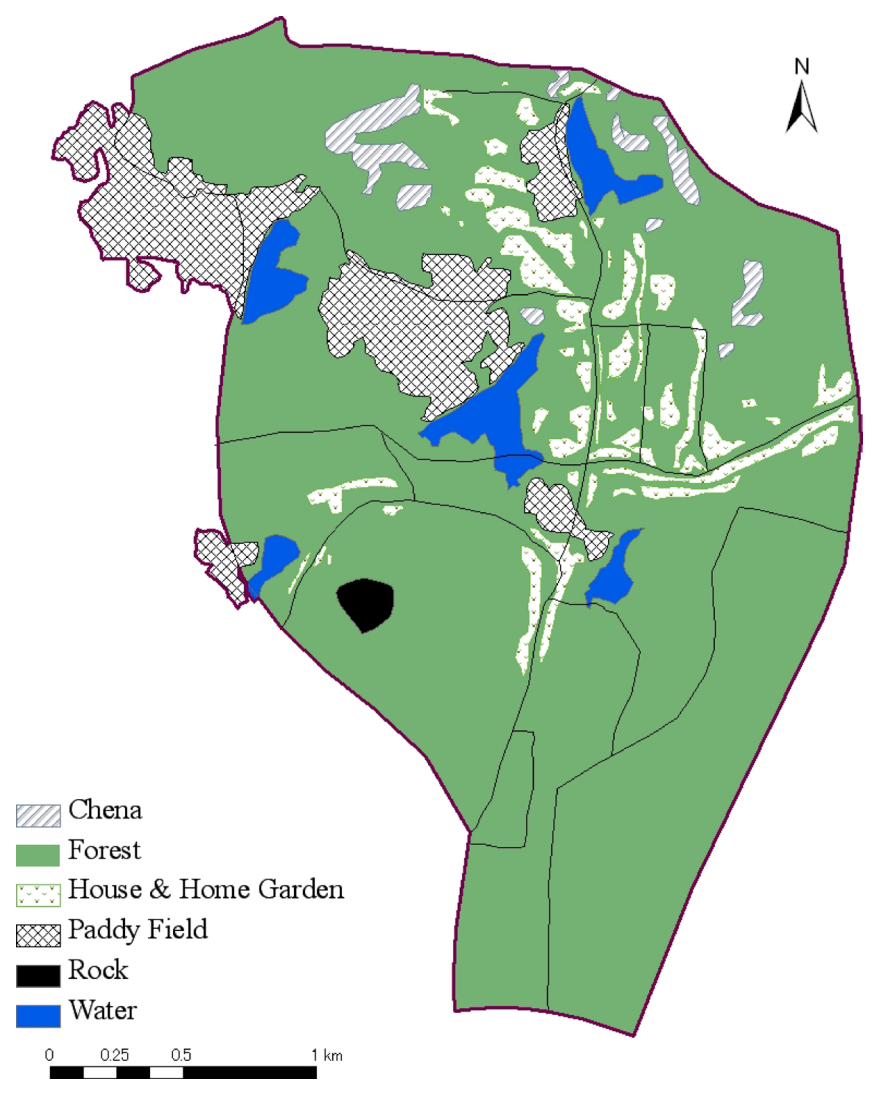

Figure 2. Land use in Pidurangala in 2009.

land ownership per family was 1 acre to 1.5 acres. $6 \%$ of the population was working in hotels outside Pidurangala and the rest was involved in such work as industrial labor, armed forces, retail shop, driver, carpenter, electrician, mason, Government and semi-governmental work such as post office.

The total land area of Pidurangala was 763 hectares. Forest land covered $77 \%$ of the total land and the cultivated land covered about $13 \%$ of the area. Further, houses and home gardens covered $6 \%$ and the water sources such as lakes and tanks were about $4 \%$ of the land. Pidurangala has two main seasons; dry season from May to September and rainy season from October to April. Accordingly, three types of agriculture were practiced in the area.

\section{Paddy cultivation}

This type of agriculture was carried out in the rainy season. Paddy fields were located close to the water sources and the people in Pidurangala cultivated rice using rain water. Rice matured by the end of the rainy season and was harvested during February to April (Figure 3). The rice harvest was for home consumption as well as for sale. Harvest was measured in "Bushels" (a kind of basket). One Bushel was equal to $20 \mathrm{~kg}$. The average rice harvest per family was about $70-80$ bushels $(1400-1600 \mathrm{~kg})$.

\section{Home gardening}

Home gardens were located around the houses and contained vegetable plots mainly for home consumption and for sale if there was any excess. Vegetables such as onion, tomato, pumpkin, cucumis melo (kind of melon) and green chili were grown in home gardens. People started home gardening mainly in the dry season after the rice harvest (Figure 3).

\section{Slash and burn cultivation (Chena)}

This was a traditional method used to grow vegetables in the dry season. In this method a plot about a hectare in the forest was burned and cleared for cultivation. The same plot was used for about three years and then abandoned for about 10 years until the regeneration of forest. There were only a very few chena in Pidurangala due to the restrictions of forest clearing after the sanctuary establishment. Therefore, this method is not commonly practiced or allowed in the area at present.

\section{Types of HEC Incidents and Patterns of Occurrence}

Past data or previous research about HEC in Pidurangala were not available except for a few records. As Perera (2009) explains, there is an inadequate HEC 


\begin{tabular}{|c|c|c|c|c|c|c|c|c|c|c|c|c|}
\hline Crop & May & Jun & Jul & Aug & Sep & Oct & Nov & Dec & Jan & Feb & Mar & Apr \\
\hline Rice & & & & & & 9 & -4 & & & & & \\
\hline Sesame & & & & & & 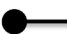 & & & & . & & \\
\hline Mustard & & & & & & & & & & & & \\
\hline & & & & & & & & & & & & \\
\hline $\begin{array}{l}\text { Finger } \\
\text { Millet }\end{array}$ & & & & & & 0 & & & & 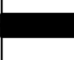 & & \\
\hline Onion & 8 & & & & & & & & & & & \\
\hline Tomato & 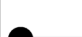 & & & & & & & & & & & \\
\hline & & & & - & & & & & & & & \\
\hline Pumpkir & 8 & & & & & & & & & & & \\
\hline Cucumis & & & & & & & & & & & & \\
\hline Melo & & & & & & & & & & & & \\
\hline $\begin{array}{l}\text { Green } \\
\text { chili }\end{array}$ & 0 & & & -1 & & & & & & & & \\
\hline
\end{tabular}

Figure 3. Crop calendar of Pidurangala.

Source: Field survey in March, 2009.

data base in Sri Lanka, and only recently some work has been carried out. Therefore, an investigation for one year was conducted in this study to record the HEC incidents on a daily basis by using an enumerator reporting system. Further, field interviews were conducted to learn about past incidents and attitudes of local residents.

Two main types of HEC incidents could be identified; elephant-induced damage on humans and humaninduced damage on elephants.

\section{Elephant-induced damage on humans}

There were 54 incidents of this type during the study period. These incidents could be further divided into four subcategories; crop damage (63\%), property damage (33\%), human death (4\%) and other impacts which were difficult to quantify.

\section{Crop damage}

There were two peaks in the occurrence of crop damage incidents: the first peak in July to September and the second from February to April (Figure 4). As shown in the crop calendar (Figure 4), the period from July to September was the vegetable maturing and harvesting time and the period from February to April was the rice maturing and harvesting time. Consequently, many vegetable damage incidents were recorded during the first peak, whereas damage to rice fields by elephants was recorded during the latter. Therefore, the pattern in the occurrence of the crop damage reflected the agricultural pattern of



Figure 4. Monthly crop damage incidents from May 2009 to April 2010.

Source: Damage report forms.

Pidurangala ${ }^{2}$.

Further, the proportion of incidents for each crop showed how elephants chose crops in Pidurangala (Figure 5). Rice was the worst affected crop followed by vegetables such as pumpkin, melon, onions and tomato. However, sesame, mustard and green chili were affected to a relatively lesser extent. Further, onions, green chili and mustard were not consumed by elephants (Figure 6) and the damage occurred as elephants walked through the fields. In other words, these three crops were not preferred by elephants. On the other hand, $79 \%$ of the rice 


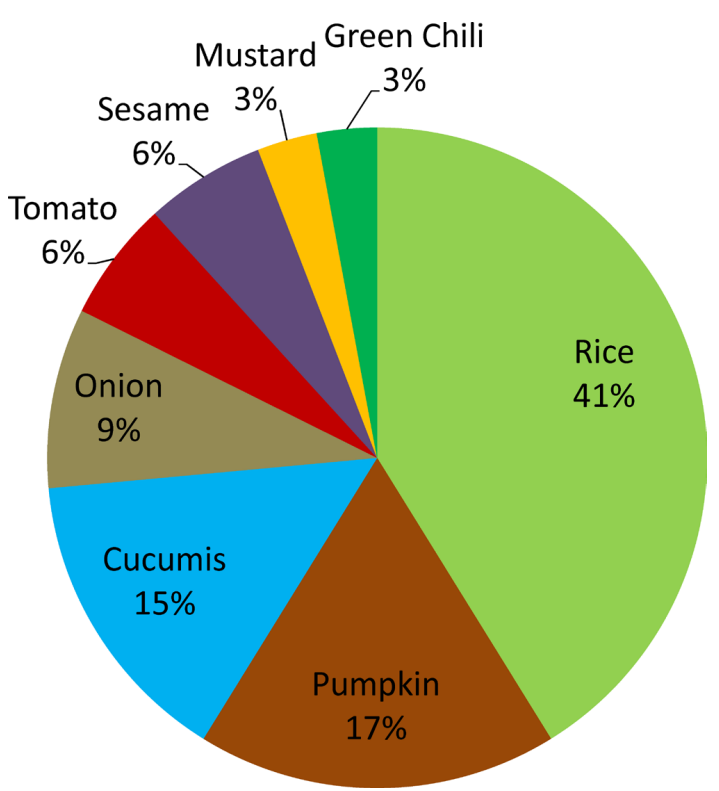

Figure 5. Share of damaged crops. Source: Damage report forms.

damage was caused by consumption and only a few cases of trampling were recorded. At the same time, pumpkin, melon and tomato were also damaged by consumption and could be identified as vegetables preferred by elephants.

The average land ownership for rice cultivation per family was about 1.25 acres. According to the farmers, about $1500 \mathrm{~kg}$ of rice can be harvested from 1.25 acres (200 perch) of cultivation. In most cases of rice damage incidents, an area of 20-30 perches was consumed by elephants (Figure 7) which was about $150-225 \mathrm{~kg}$ of rice harvest from a field or a $10 \%-15 \%$ of total rice production of a family. Therefore, approximately $13 \%$ of the rice cultivation in Pidurangala was consumed by elephants.

Further, $82 \%$ of the crop damage incidents were caused by groups of four or fewer elephants (Figure 8). These groups were mainly family units of females and calves. Solitary male elephants were responsible for $15 \%$ of the crop damage incidents. This result showed the composition of the elephant population in Pidurangala. At the same time, this is a different result from other regions. In many HEC areas in Sri Lanka, crop raiding was caused by solitary male elephants as they appear to take higher risks of entering into the human areas than female elephants and calves (Sukumar and Gadgil 1988). In Pidurangala, paddy fields were located away from the housing area and easily accessible for elephants from the lakes and tanks, along with the forest. Most of the crop damage incidents took place in the late evenings to early mornings and none during the day time (Figure 9). This pattern of occurrence has created great difficulty in guarding

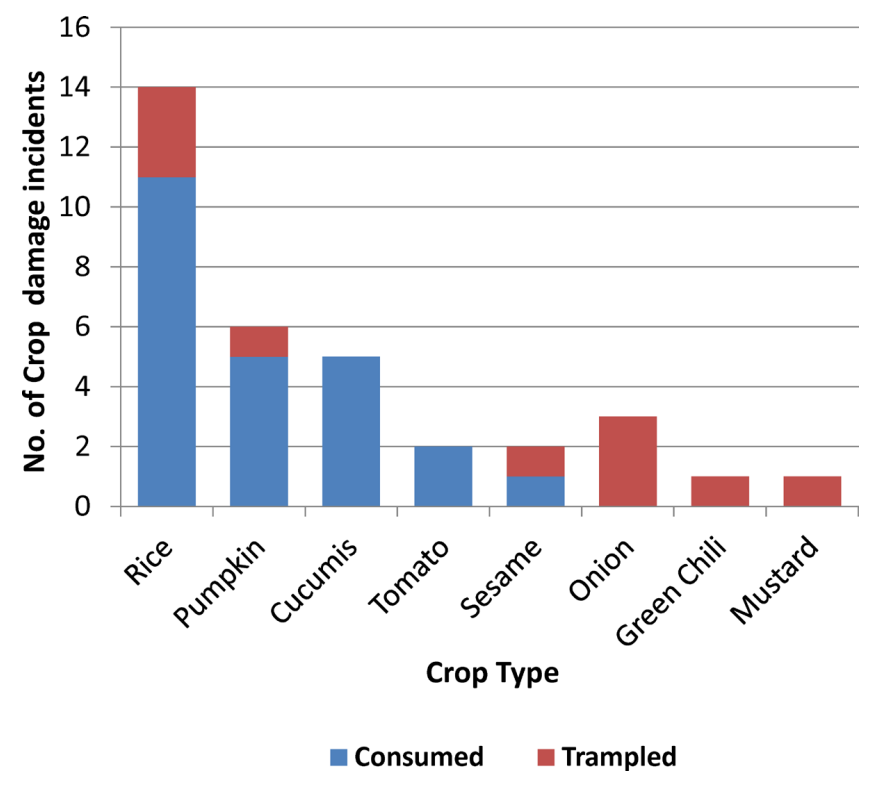

Figure 6. Type of crop damage by elephants for each crop.

Source: Damage report forms.

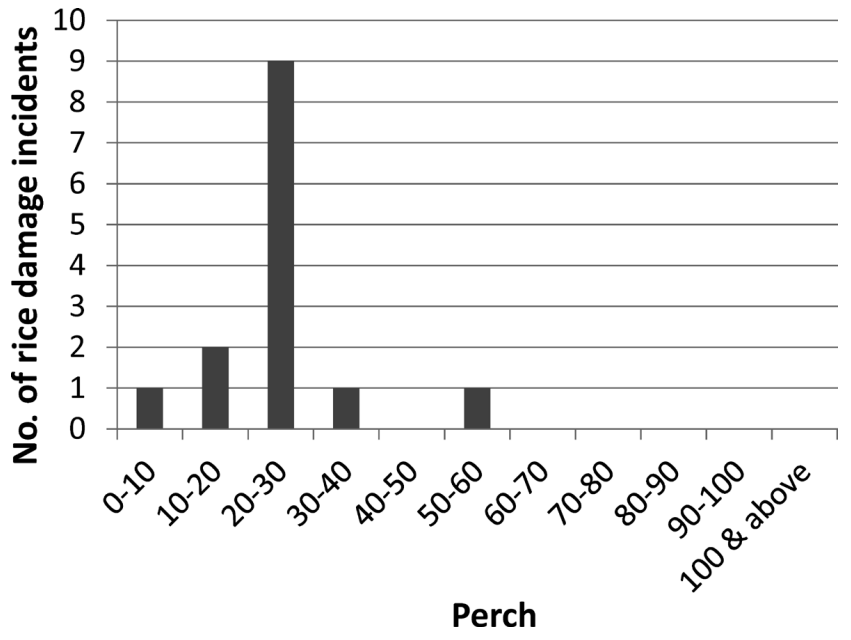

Figure 7. Size of damaged rice fields.

Source: Damage report forms.

crops from elephants because the farmers were required to leave their houses and be in the fields throughout the night.

\section{Property damage}

Property damage incidents accounted for $33 \%$ of the total elephant-induced damage. Elephant attacks on houses were high from July to September (Figure 10). The main reason is the high rate of rice storage in houses during this period (Figure 11). People in Pidurangala usually store their rice harvest in their houses as there aren't any separate storage facilities in the area. Elephants broke into the houses to consume rice. At the same time, there were vegetables in the home gardens during this period. $27 \%$ 


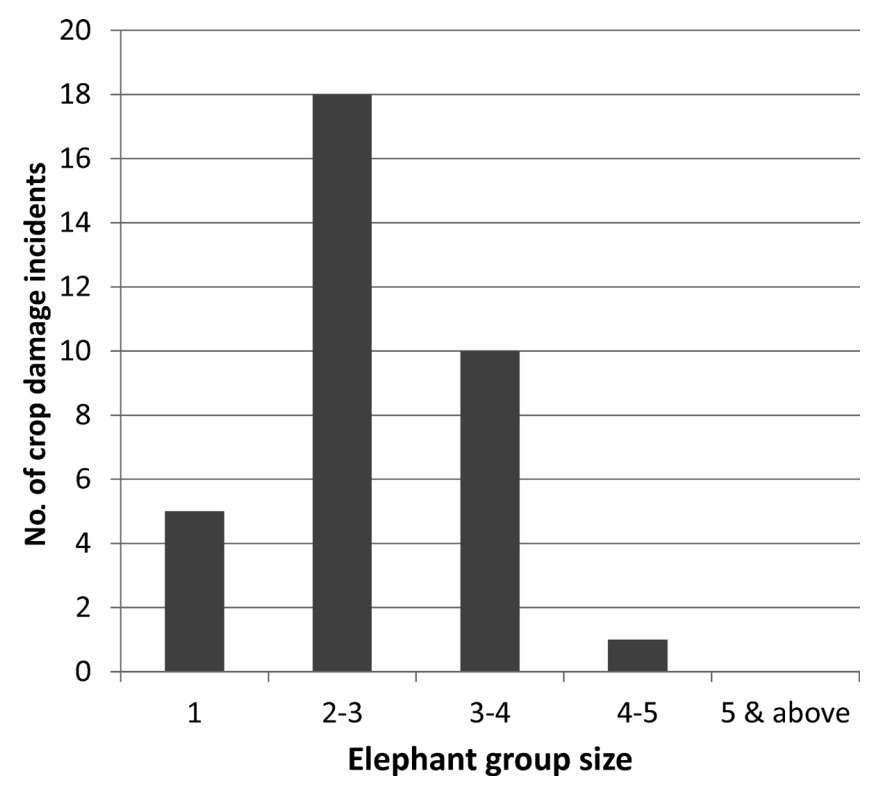

Figure 8. Group size of elephants causing crop damage.

Source: Damage report forms.

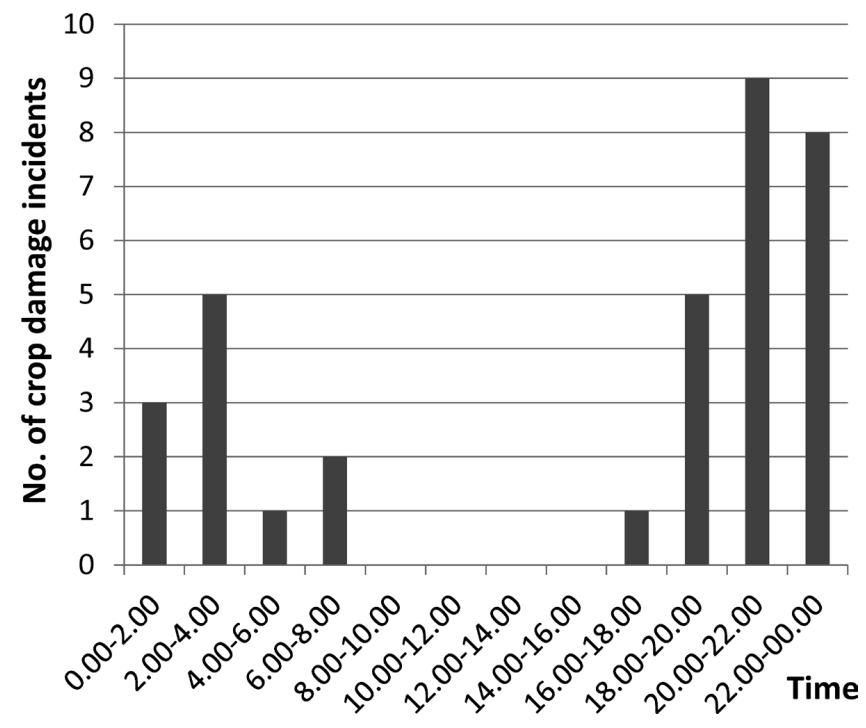

Figure 9. Time distribution of crop damage incidents. Source: Damage report forms.

of the vegetable damage incidents occurred along with the property damage (Figure 12). Therefore, property damage is a consequence of elephants targeting the rice harvest in houses and vegetables in the home gardens.

Group size of elephants involved in property damage was different from crop damage cases. Solitary male elephants were involved in most of the property damage cases (Figure 13). Family groups of elephants with females and calves rarely moved into the housing area. The time of the occurrence of these incidents showed a similar pattern to the crop damage incidents and took place mainly between 10 p.m. to 4 a.m. (Figure 14).

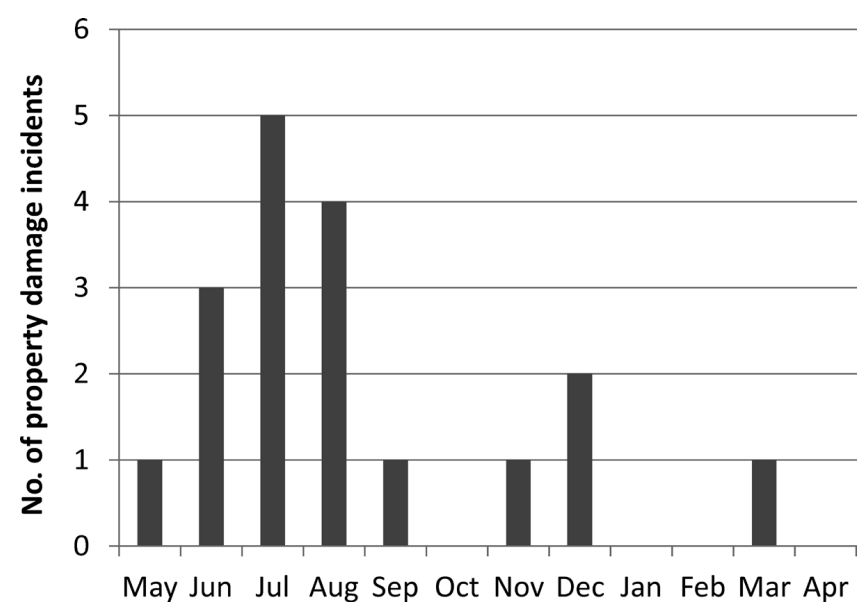

Figure 10. Monthly property damage incidents from May 2009 to April 2010.

Source: Damage report forms.

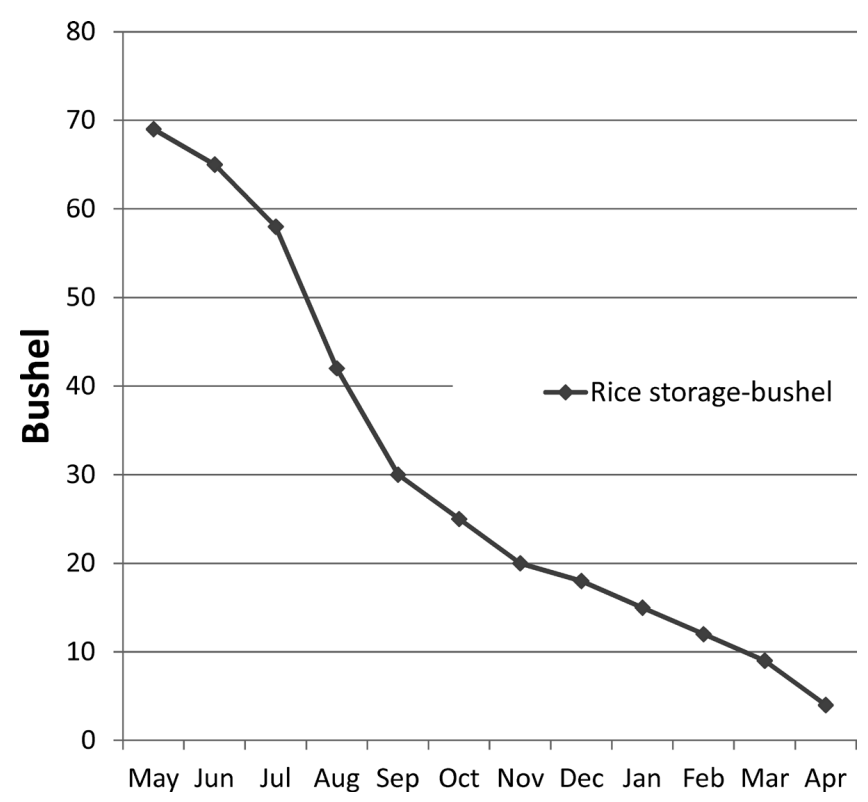

Figure 11. Average monthly rice storage per family. Source: Field interviews.

\section{Human death}

Two incidents resulting in human death were recorded during the study period and this type of damage was the lowest among elephant-induced damage incidents. One person died in July 2009 and the other person in February 2010. According to the interviews with local residents, the two victims were the first to die in elephant attacks in this area. The death in July occurred during a house attack around 3 a.m., and the death in February occurred during crop damage in a paddy field between 8 p.m. to 10 p.m. The elephants involved in these two incidents were two male elephants. These victims were new comers to Pidurangala and had lived there for only a few months. People pointed out that the two new comers 


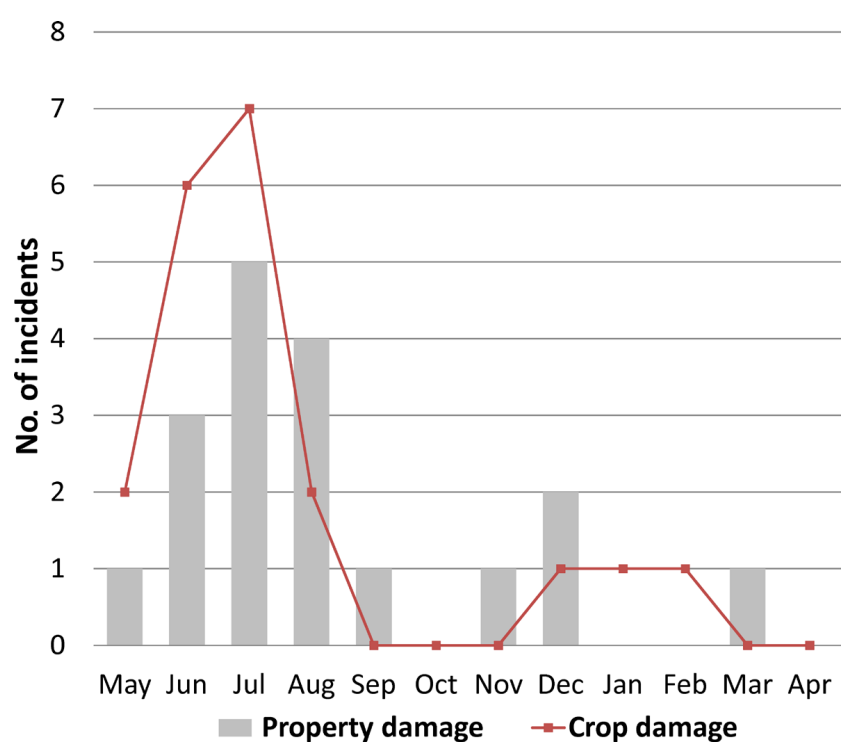

Figure 12. Monthly property damage and crop damage incidents.

Source: Damage report forms.

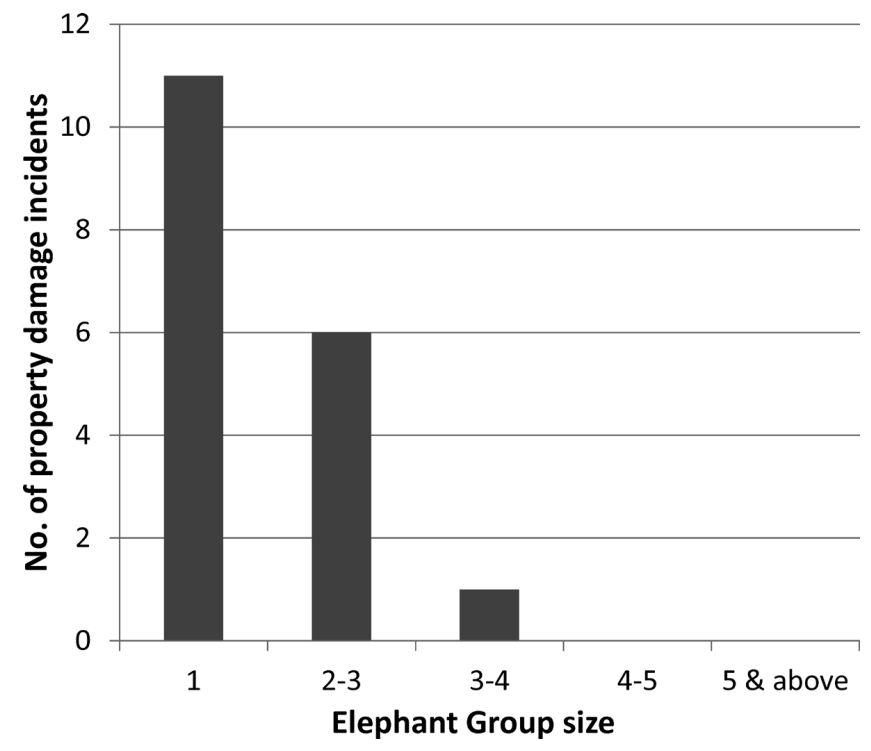

Figure 13. Group size of elephants involved in property damage.

Source: Damage report forms.

were not familiar with how to escape from elephant attacks. According to the local residents, when an elephant enters a paddy field it is necessary to make noise and disruption to chase the animal away. However, in case of a property, one must stay calm and leave the place quietly because the elephant itself is nervous in an unfamiliar environment such as a housing area. The two new comers failed to act appropriately according to these scenarios.

There were only five newly settled families (15 people) in Pidurangala. Others have been living in the area for a long period of time and have a deep knowledge about elephants. For example, they were able to recognize the

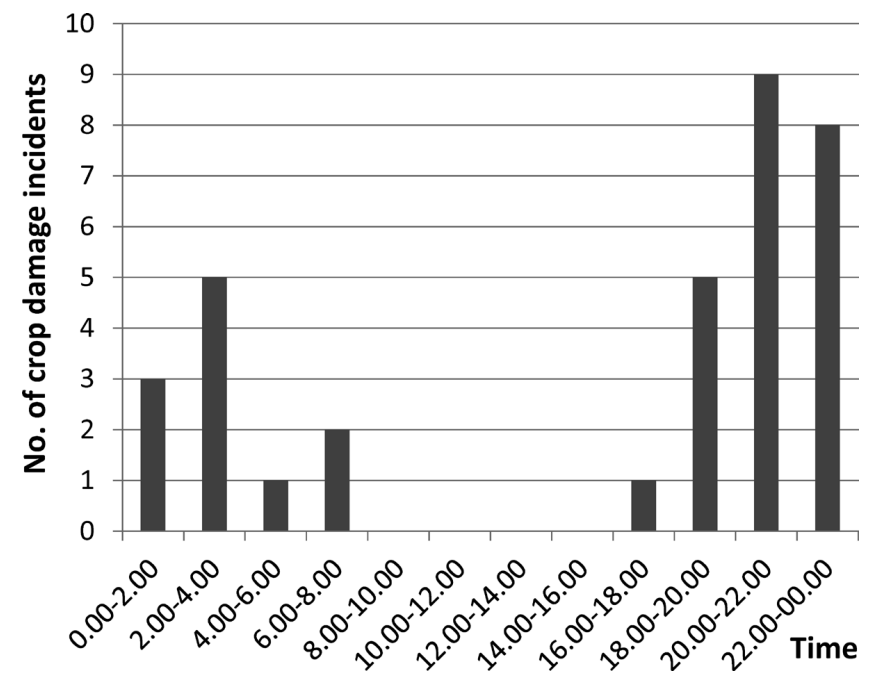

Figure 14. Time distribution of property damage incidents.

Source: Damage report forms.

existence of elephants from the smell, the sound of footsteps and breaking leaves and branches of trees even in the night. People also said that they can identify the age of an elephant at a glance. However, this knowledge was acquired naturally by living in the area from childhood and there was no system of sharing the knowledge with new comers.

\section{Other impacts on humans}

The three types of damage described above represent the direct impact of HEC on people. It was also possible to identify the indirect impact of the issue as well.

All the farming families who participated in the interviews said that they suffer from inadequacy of sleeping hours due to the guarding of farms and properties at night. At the same time, HEC had negatively impacted on people's social life. For example, people were unable to go out in the evening as there was a high risk of encountering elephants in the evening. Almost all the elephant-induced damage incidents occurred in the evening to early morning. There was no electricity supply along many roads in Pidurangala. Therefore, evening activities were avoided by people considering the safety of their lives. Moreover, wives and children were left alone in houses at night as husbands had to leave for paddy fields to guard crops. Some husbands explained that they wished they could spend more time with their families and some hadn't seen their children for many days because when they returned home from the fields in the morning, their children had gone to school, and when the children returned from school, farmers had returned to the fields. On the other hand, according to a school teacher in the 


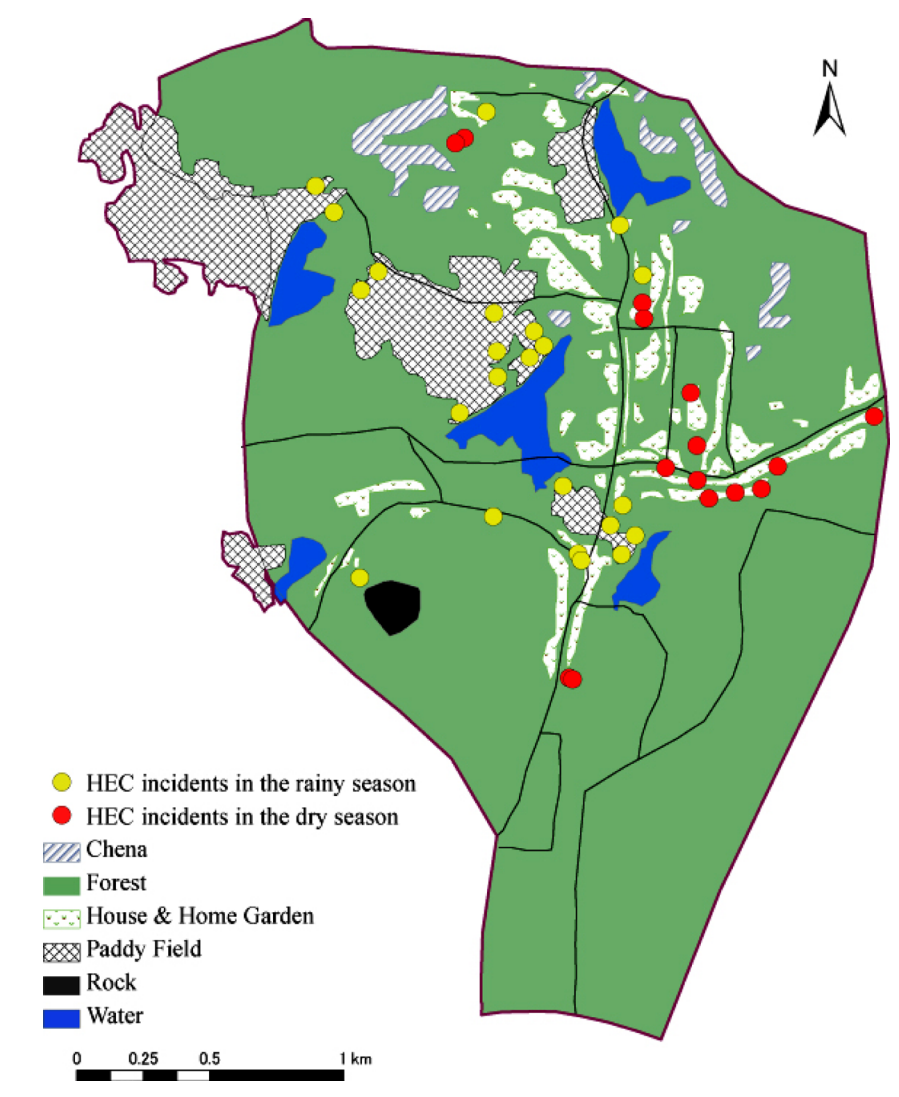

Figure 15. Spatial distributions of HEC incidents in Pidurangala. Source: GPS survey in March 2010.

area, school attendance of some children was very poor especially during the rice maturing and harvesting time. These children had to help their parents in guarding the crops and properties in order to secure their living. Fear of elephant attacks was another issue. Especially, many families were worried and fearful until their children returned from school in the evening and did not allow after-school activities for children.

Thus, these indirect impacts of HEC have increased people's intolerance towards elephants and resulted in a negative relationship with elephants.

\section{Spatial distribution of the elephant-induced damage incidents}

Distribution of incidents in the area was identified based on the agricultural pattern of the two seasons.

As shown in the Figure 15, incidents in the rainy season were concentrated in the paddy fields. Rice cultivation was conducted during the rainy season. The fields were located close to water sources in the area. These tanks and lakes collect rain water for agriculture. At the same time, the tanks and lakes were often accessed by elephants for their water requirements. Therefore, the fields closer to water were more vulnerable to crop raiding than the other fields. The fields at approximately 50 meters distance from water were mostly accessed and raided by elephants.

On the other hand, incidents in the dry season were mainly concentrated in the housing area. Water sources dried up in this period and there was not enough water for paddy cultivation. As a result, farmers abandoned the paddy fields in the dry season and there was no other crop in the fields. However, rice harvest was stored in houses for consumption until the next rainy season, and also home gardening of vegetables was carried out in the dry season, which attracted elephants to the housing area. However, as described in a previous section, it was mainly the solitary male elephants that had caused damage in the housing area as they tended to take higher risks and also walked far away from their territories looking for food. Location of houses away from the fields and sources of water had protected them from damage by elephant groups.

The above results suggest that the distribution of elephant-induced damage on people was closely related to availability and the accessibility of crops.

\section{Human-induced damage on elephants}

Two sub categories of this type of incidents could be identified; elephant injury and elephant death. 
Three elephants were killed and seventeen elephants were injured by people in the conflict from May 2009 to April 2010. Two of the three killings of elephants had taken place during the period of June to August. Elephants were poisoned, shot and electrocuted in the killings. As described under "Property damage", the period of June to August also recorded the highest number of house attacks by elephants. This shows that people had taken violent deterrent methods to avoid property damage by elephants and reflects the level of intolerance of people towards property damage. Injuries to elephants were caused by gun traps and sharp nail traps set by people.

These elephant deaths and injuries were the cases which came into the investigation of wildlife authority in the area, but the number of such incidents may be even higher as there were many cases which had been difficult to discover. According to the wildlife authority, many incidents of this type were hidden by the people to avoid fine and imprisonment. Besides the area is protected by law under the Fauna and Flora Protection Ordinance, people had gone beyond the rules and regulations to harm the elephants in order to protect their crops and properties, explaining the fact that the rules alone could not conserve elephants and the support from local residents was also highly essential.

\section{Counter Measures Adopted by the Local Residents}

Some counter measures are practiced by local residents to deter problems from elephants. These methods include watch posts, lighting, noise, biological fences, and avoidance of night outings.

Watch posts were small huts built on tall trees in the fields to guard crops in the night. These huts have space for one or two people. Farmers stay awake in these watch posts and shout or make noise by throwing fire crackers whenever elephants try to enter the fields. Fire, kerosene lamps, flash lights are also used to frighten and chase away the elephants. However, these methods have been ineffective as some elephants get used to these lights and sounds in the long run. In extreme cases, farmers shoot, set traps or electrocute elephants to protect their crops, properties and lives.

In some houses, biological fences were built around the houses with Euphorbia plants. These fences are often called live fences and work as a barrier for elephants in entering the houses. However, there were cases where some elephants have destroyed the fences by uprooting and throwing trees. There is also a practical difficulty in fencing larger plots (one to two acres) by Euphorbia plants.

Most of the elephant-induced damage on people occurs in the evenings. Therefore, people avoid night outings or activities and try to stay indoors after 5 p.m.

\section{Counter Measures Adopted by the Government}

Two government authorities are in charge of HEC relevant matters in the area; Divisional Secretariat (ward office) and the branch office of the Department of Wildlife Conservation of Sri Lanka (DWCS). These two authorities have implemented a compensation scheme for the victims of elephant attacks. The main aim of the compensation system is to increase the tolerance of people towards elephants and to reduce elephant killings and injuries. Sri Lankan elephants are an endangered species and national efforts are being made for elephant conservation. The compensation for crop damage and property damage was up to a maximum of 20,000 rupees (USD 200). However, local people complained that it takes a long processing time to receive the money. Compensation for human death or injury was an amount of 100,000 rupees (USD 1000). This again has created a conflicting attitude in people as the fine for killing an elephant was 150,000 rupees to 500,000 rupees, high above the value for a human death.

DWCS provides fire crackers for people to chase away the problem elephants. People were not satisfied with the quantity they received and at the same time, some elephants were already used to the crackers and not afraid of the sound.

DWCS has also built an electric fence in the area to stop elephants moving in to the fields and houses (Figure 16). The fence was located in the forest. This location of the fence has created some issues for people as well as elephants. For people, the electric fence has become a barrier to access the forest to collect firewood, fruits and medicinal plants. Thus the separation of village and forest by the fence has directly influenced the lifestyle of people. As a result, people were strongly against the location of the fence and never supported its maintenance. Gunaratne and Premarathne (2006), in their analysis of the effectiveness of the electric fencing in HEC areas in Sri Lanka identified that the effectiveness of an electric fence depends on the social acceptance of the fence and the community support for its maintenance. Electric fencing in Pidurangala cannot be identified as an effective 


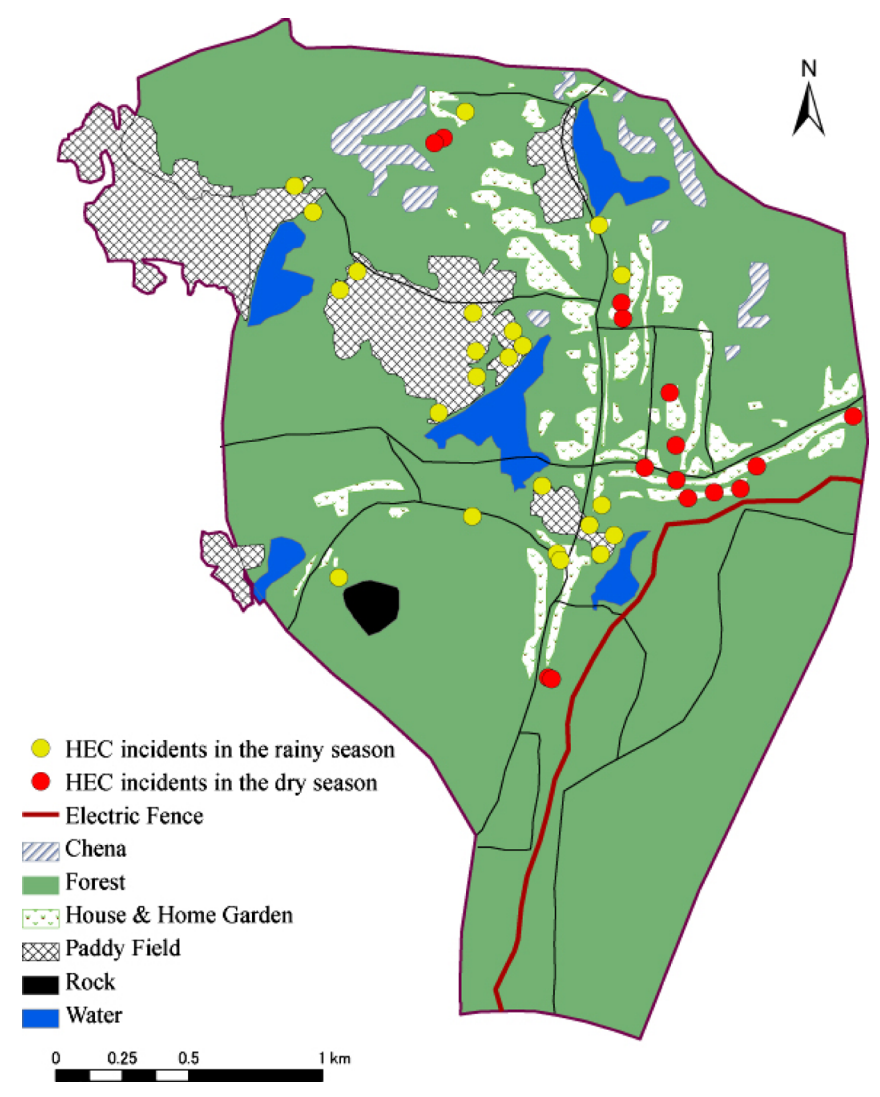

Figure 16. Electric fence in Pidurangala.

Source: GPS survey in March 2010.

method because people did not accept the fence and did not extend their support for its maintenance. On the other hand, the location of the fence has also influenced the elephants negatively as it blocks the elephant paths in accessing water tanks and lakes. People in Pidurangala have been demanding that the government relocate the fence into the housing area to protect their houses with the willingness to support the maintenance of the fence.

\section{Local People's Perspective of HEC}

Pidurangala became a sanctuary in 1990. Prior to the sanctuary establishment, a traditional agricultural method called slash and burn cultivation was commonly practiced in the area. In this method a plot of forest is burned and cleared for cultivation. The same plot is used for about three years and then left for about 10 years for the purpose of forest regeneration. This type of cultivation was mainly conducted in the dry season and people have had a custom of sharing the harvest with wildlife. A certain amount of harvest was left for elephants depending on the size of the cultivation.

After the sanctuary establishment, clearing forest, cutting trees for cultivation or any other purpose were completely prohibited along with various other restrictions.
As a result, people had to give up their traditional slash and burn cultivation. In the past, plots of slash and burn cultivation covered $7 \%$ of the total land where as the current share is only $2 \%$. People started home gardening of vegetables as an alternative method to slash and burn cultivation. As described under the "property damage", vegetables in the home gardens have become a cause for elephants to move into the housing area.

Figure 17 shows the flow of communication between the local residents and the government authorities when a damage incident by elephants occurs. People contacted the GN officer (public administrative officer in charge of public administration in the area) or the police to inform about the problem and to get the compensation for the damage. Then the GN officer and the police informed the ward office and the DWCS. In some cases people contacted the ward office directly during their visit to the ward office for several other purposes such as permits and licenses. However, there wasn't any direct communication between the local people and the wildlife authorities. The main reason for this distance is the new rules and regulations regarding wildlife conservation and the change in traditional livelihood. People are not involved in the conservation process or decision making. These factors have intensified the HEC in Pidurangala. 


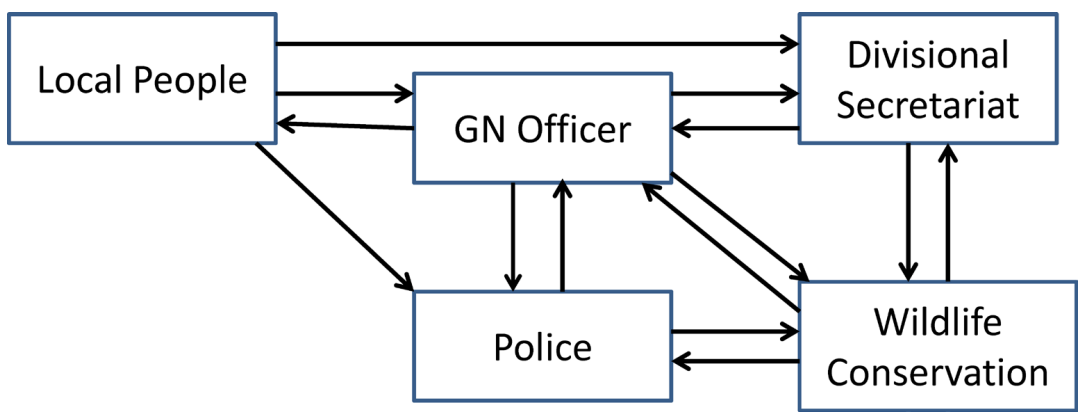

Figure 17. Communication of damage incidents between local people and authorities. Source: Interview survey.

\section{Discussion}

HEC in the region has negative impacts on both people and elephants.

Crop damage was the most common form of damage to the people by elephants. It is important to see the reason why elephants raid crops. Food crops provide more crude protein and more nutrition than do wild forage (Barnes 1983; Fernando et al. 2005). This was also obvious in the selection of food crops by elephants in Pidurangala such as rice, pumpkin, tomato and melon. The spatial distribution of elephant-induced damage incidents was also related to the availability of crops. Further, the paddy fields closer to water were highly vulnerable for crop raiding due to the easy accessibility for elephants. The occurrence of crop raiding in the fields can be predicted based on the distance from water to the field.

Property damage incidents were few compared to the crop damage incidents. However, people have taken violent measures to stop house attacks from elephants compared to the crop damage and elephant killings were high during the period of property damage. Property damage involves a higher cost for farmers and influences their social lives.

Even though people and wild elephants live within the same sanctuary, human death and injuries were low compared to other regions in Sri Lanka. For example, Santiapillai et al. (2010) revealed human fatalities by elephants in five regions in Sri Lanka; Northwestern, North Central, Central, Eastern and Eva provinces and found that 45 people were killed by wild elephants in 2008, but none were reported from the Central Province. People have a deep knowledge about elephants due to their direct co-existence with elephants in the same area, and know how to save their lives from elephant attacks. However, there is no system of sharing this knowledge with the new-comers or other regions which resulted in deaths to two new settlers in the area.
There was a difference in the group size of problem elephants compared with the cases in other regions in Sri Lanka. In many HEC areas in Sri Lanka, solitary male elephants were reported to cause most of the damage incidents to people, because they appear to take the higher risks of leaving the park boundaries and entering into the human areas than female elephants and calves (Sukumar and Gadgil 1988). In the Pidurangala case, people and wild elephants live in the same area. However, while paddy fields are located away from the housing area, the fields are located near lakes and water tanks. Therefore, paddy fields are easily accessible for elephants compared to the housing area. Consequently, paddy fields were often raided by family groups of elephants whereas property damage was caused by solitary male elephants that tend to take higher risks in finding food.

Another characteristic of HEC in Pidurangala is the change in people's attitude towards elephants due to the changes in traditional life after the establishment of the sanctuary. Living within a protected area under various restrictions while at the same time losing the freedom of traditional livelihood while facing threats of wild elephants create intolerance and a negative attitude in people towards elephants as well as wildlife authorities. Based on the results of the study, some suggestions can be made as areas to be considered for the mitigation of the conflict.

Firstly, it is important to understand the people's tolerance level towards the damage by elephants. Crop damage is not a new phenomenon for people in the area because they have been sharing the crops with elephants in the past. In wildlife areas, people expect a certain amount of crop damage by wildlife (Knight 1999). People's support for elephant conservation can be obtained by allowing the traditional cultivation methods and valuing the traditional conservation methods of people. Traditional agricultural practices allow a harmonious relationship between people and elephants through resource portioning (Fernando et al. 2005). Therefore, investigations are required 
to learn about the appropriate application of the traditional agricultural methods again in Pidurangala. Further, property damage incidents by elephants have caused the highest intolerance in people as property damage involves higher costs for farmers and also affects the lives of their families and children. Therefore, a system to protect the houses should be implemented. Relocation of the electric fence to the housing area has been a continuous demand by local residents. The wildlife authorities can also receive support from the people in maintaining the fence.

Human death and injury were significantly low in the area. Only the new comers have become victims so far. Educational programs for new settlers about elephant behavior and the means of protecting life from elephants are required. These programs can be organized with the active involvement of local residents to share their experience and knowledge about elephants with new settlers. This is also a possible way of improving the communication and the relationship between the people and the wildlife authorities.

Conservational rules and regulations alone have failed to mitigate the issue in this case. It is important to value the traditional livelihood and gain community support and active involvement for decision making process and conservation.

\section{Notes}

1. Sri Lanka underwent a civil war until 2009 and it was not possible to conduct surveys or research in many areas: only recently some work has been carried out. A census on elephant population was carried out in 2011, but the results are still under debate. As a consequence, the total number of wild elephants in Sri Lanka or in each elephant habitat in the country is still uncertain. Pidurangala is in the same situation, and due to the unavailability of data, it was not possible to conduct a comparative study prior to or after the sanctuary establishment. The study therefore relies on information obtained from interviews with local residents and recording the damage incidents for a period of one year.

2. The main natural food for elephants in the wild is grass. Availability of wild forage is subject to seasonal variations, with ample resources during the rainy season and scarcity during the dry season. However, elephants in agricultural areas depend less on wild forage as most manifest a strong preference for food crops which are richer in nutrients than wild forage. Therefore, the pattern of HEC incidents shows a strong relation to the availability of food crops than to wild forage.

\section{References}

Barnes, R. F. W. 1983. Effects of elephant browsing on woodlands in a Tanzanian national park: Measurements, models and management. Journal of Applied Ecology 20: 521-540.

Barnes, R. F. W. 1996. The conflict between humans and elephants in the central African forests. Mammal Review 26(2): 67-80.

Desai, A. A. 1998. Management strategies for conservation of elephants and mitigation of human-elephant conflict. Sri Lanka: Department of wildlife conservation.

Distefano, E. 2005. Human-Wildlife conflict worldwide: Collection of case studies, analysis of management strategies and good practices. Rome: FAO.

Fernando, P., Wickramanayake, E., Weerakoon, D., Jayasinghe, L. K. A., Gunawardena, M. and Janaka, H. K. 2005. Perceptions and patterns of human-elephant conflict in old and new settlements in Sri Lanka. Biodiversity and Conservation 14: 2465-2481.

Gunaratne, L. P. H. and Premarathne, P. K. 2006. The Effectiveness of electric fencing in mitigating human-elephant conflict in Sri Lanka. Singapore: Economy and environment program for Southeast Asia (EEPSEA).

Hoare, R. E. 1999. Determinants of human-elephant conflict in land use mosaic. Journal of Applied Ecology 36: 689-700.

Ishwaran, N. 2001. Integrating elephant conservation with protected area management in Sri Lanka. Gajah 20: 27-38.

Kiiru, W. 1995. The current status of human-elephant conflict in Kenya. Pachyderm 19: 15-18.

Knight, J. 1999. Monkeys on the move: The natural symbolism of people-Macaque conflict in Japan. Asian Studies 58: 622-647.

Parker, G. E. and Osborn, F. V. 2001. Dual season crop damage by elephants in the Eastern Zambezi Valley, Zimbabwe. Pachyderm 30: 49-56.

Perera, B. M. A. O. 2009. The human-elephant conflict: A review of current status and mitigation methods. Gajah 30: 41-52.

Santiapillai, C., Wijeyamohan, S., Bandara, G., Athurupana, R., Dissanayake, N. and Read, B. 2010. An assessment of the human-elephant conflict in Sri Lanka. Cey. J. Sci. 39(1): 21-33.

Sitati, N. W., Walpole, M. J., Smith, R. J. and Williams, N. 2003. Predicting spatial aspects of human-elephant conflict. Journal of Applied Ecology 40: 667-667.

Sukumar, R. and Gadgil, M. 1988. Male-female differences in foraging on crops by Asian elephants. Animal Behaviour 36: 1233-1255. 